\title{
Erratum to: Elephants Also Like Coffee: Trends and Drivers of Human-Elephant Conflicts in Coffee Agroforestry Landscapes of Kodagu, Western Ghats, India
}

\author{
P. Bal · C. D. Nath $\cdot$ K. M. Nanaya \\ C. G. Kushalappa $\cdot$ C. Garcia
}

Published online: 13 July 2011

(C) Springer Science+Business Media, LLC 2011

\begin{abstract}
Kodagu district produces 2\% of the world's coffee, in complex, multistoried agroforestry systems. The forests of the district harbour a large population of the Asian elephant (Elephas maximus). The combined effects of high elephant density and major landscape changes due to the expansion of coffee cultivation are the cause of human-elephant conflicts (HEC). Mitigation strategies, including electric fences and compensation schemes implemented by the Forest Department have met with limited success. Building on previous studies in the area, we assessed current spatial and temporal trends of conflict, analysed local stakeholders' perceptions and identified factors driving elephants into the estates. Our study, initiated in May 2007, shows that the intensity of HEC has increased over the last 10 years,
\end{abstract}

The online version of the original article can be found under doi:10.1007/s00267-011-9636-1.

For reason beyond the control of the authors or the editors, the article titled "Elephants Also Like Coffee: Trends and Drivers of HumanElephant Conflicts in Coffee Agroforestry Landscapes of Kodogu, Western Ghats, India" by P. Bal, C.D. Nath, K. M. Nanaya, C. G. Kushalappa, C. Garica (DOI: 10.1007/s000267-011-9636-1) was published in the regular issue Vol. 47 issue 5 instead of this special issue, where it was originally scheduled to appear. Therefore the full article is reprinted here.

P. Bal · C. D. Nath · K. M. Nanaya - C. Garcia

French Institute of Pondicherry, 11 St Louis Street, PB 33,

Pondicherry 605001, India

P. Bal

School of Biology, Bute Building, University of St Andrews, St Andrews, Fife, KY16 9AS, UK

C. G. Kushalappa

College of Forestry, University of Agricultural Sciences

(Bangalore), Ponnampet, Kodagu District, Bangalore 571216,

Karnataka, India exhibiting new seasonal patterns. Conflict maps and the lack of correlation between physical features of the coffee plantations and elephant visits suggest elephants move along corridors between the eastern and western forests of the district, opportunistically foraging when crossing the plantations. Dung analyses indicate elephants have selectively included ripe coffee berries in their diet. This is, to our knowledge, the first report of wild elephants feeding on coffee berries. If this new behaviour spreads through the population, it will compound an already severe conflict situation. The behavioural plasticity, the multiplicity of stakeholders involved, the difficulty in defining the problem and the limits of technical solutions already proposed suggest that HEC in Kodagu has the ingredients of a "wicked" problem whose resolution will require more shared understanding and problem solving work amongst the stakeholders.

Keywords Asian elephant - Crop raiding - Coffee estates $\cdot$ Wicked problem $\cdot$ Dung analysis

\section{Introduction}

Human demographic pressure, expansion of cash crops in previously forested areas and the subsequent overlap of

C. Garcia $(\bowtie)$

CIRAD, UPR Goods and Services of Tropical Forest

Ecosystems, 34398 Montpellier, France

e-mail: claude.garcia@cirad.fr

C. Garcia

CIFOR ENV Programme, P.O. Box 0113, BOCBD,

Bogor 16000, Indonesia 
habitats, has led to the widespread exclusion of elephants from their previous ranges (Hoare and Du Toit 1999; Parker and Graham 1989; Sukumar 2006). The increase in the human-elephant interface has caused an increase in conflict (Nelson and others 2003), defined as 'any humanelephant interaction which results in negative effects on human social, economic or cultural life, on elephant conservation or on the environment' (Hoare 2001a). Crop raiding is identified as the main form of conflict (Barnes 1996; Tchamba 1996; Williams and others 2001).

In India, the Gajasastra ('elephant lore' in Sanskrit) records devastation of crops by elephants during the sixth and fifth centuries BC (Sukumar 1989). Today, HEC is reported throughout the 13 countries where the Asian elephant is distributed (Kemf and Santiapillai 2000). Local communities and the rural poor bear much of the costs of these conflicts. In Bhadra Wildlife Sanctuary (State of Karnataka, India), average losses due to elephant raids amount to $11 \%$ of the monetary value of the grain production of the affected households (Madhusudan 2003). Detailed reviews of the intensity of conflict in India can be found in Sukumar (1994) and Madhusudan and Mishra (2003).

Kodagu District is a coffee-growing region in the Western Ghats of the State of Karnataka State. It produces $2 \%$ of the world's coffee, essentially in complex, multistorey agroforestry systems (Coffee Board of India 2008). The $1,588 \mathrm{~km}^{2}$ of state-controlled forests in Kodagu harbour an estimated 1,730 elephants (Nath and Sukumar 1998). The district is surrounded by forests that extend up to the Eastern Ghats in a continuous belt that holds the single largest contiguous population of Asian elephants, with an estimated 9,000 individuals (Sukumar 1989; Vidya and others 2005). The region has 1-3 elephants per $\mathrm{km}^{2}$, one of the highest elephant densities in Asia (Kemf and Santiapillai 2000).

Along with labour costs and coffee price fluctuations, HEC is highlighted by local stakeholders as one of the three main problems farmers are facing (Garcia and others 2010). In the $4100 \mathrm{~km}^{2}$ of the district, elephants killed 55 humans between 1996 and 2005 (Fig. 1). In comparison, in Trans Mara District $\left(2,900 \mathrm{~km}^{2}\right)$ in the south west of Kenya, elephants killed 21 people between 1986 and 2000 (Sitati and others 2003), an intensity of conflict three times lower if reported to the area covered by the studies.

Previous studies on HEC in Kodagu (Nath and Sukumar 1998; Kulkarni and others 2007; Bhoominathan and others 2008) have described regional pattern of conflict and coping strategies developed by coffee planters and institutions such as the Karnataka Forest Department (KFD) to tackle HEC.

In this paper we: (1) use administrative indicators to assess recent temporal and current spatial trends in HEC in the district, updating previous studies in the region; (2) analyse stakeholders' perceptions; (3) identify the drivers that induce elephants to raid coffee estates; and (4)

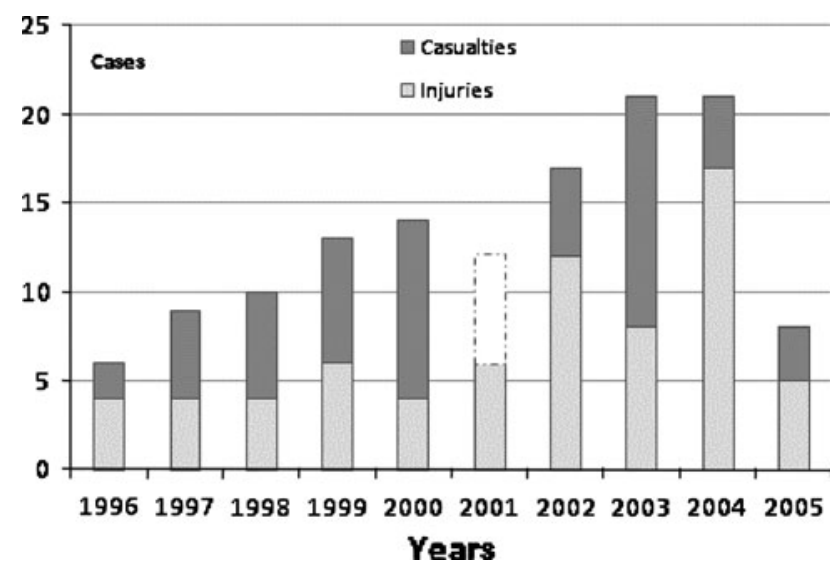

Fig. 1 Human casualties and injuries in the district of Kodagu between 1996 and 2006. Data for human casualties in 2001 is missing, and replaced by the average value (in white). Source: Karnataka Forest Department 2007

document elephant consumption of ripe coffee berries. We discuss how the concept of 'wicked problems' (Horst-Rittel and Webber 1973) can help stakeholders cope with the repeated failures of HEC mitigation in the past and develop alternative management strategies.

\section{Methods}

\section{Study Area}

The study was carried out between May 2007 and July 2008 in Kodagu district $\left(75^{\circ} 25^{\prime}-76^{\circ} 14^{\prime} \mathrm{E}, 12^{\circ} 15^{\prime}-12^{\circ} 45^{\prime} \mathrm{N}\right)$ in the State of Karnataka (India). The human population density is approximately 140 inhab. $\mathrm{km}^{2}$ (Census of India 2001). The topography ranges from 850 metres above sea level (msl) in the east to a maximum of $1,745 \mathrm{msl}$ in the west. Yearly rainfall increases westward, ranging from less than $800 \mathrm{~mm}$ to more than $5000 \mathrm{~mm}$ (Elouard and Guilmoto 2000), and occurs mainly from June to September during the southwest monsoons with lighter showers from October to December during the northeast monsoons. The vegetation changes along the rainfall and elevation gradient from dry deciduous in the east, to moist deciduous in the central area and to wet evergreen forests on the western hills (Pascal 1982). Forests represent $46 \%$ of the land area of the district. State-controlled forests, including one national park and three wildlife sanctuaries, are located along the district's periphery (Fig. 2) and their boundaries are intermittently delineated with solarpowered electric shock fences, elephant-proof trenches or both (Nath and Sukumar 1998). Coffee estates cover 33\% of the total area of the district with other associated crops, including pepper, cardamom and oranges. Terraced rice paddies occur in low-lying valley areas of the district and occupy $21 \%$ of the total area (Garcia and others 2010). They 
Fig. 2 Map of Kodagu district (with Madikeri as its capital city) showing the study area of Virajpet Forest Division used for landscape-level analysis and the smaller intensive study area to the east used for estate-level analysis. Inset shows the location of Kodagu in the peninsula of southern India

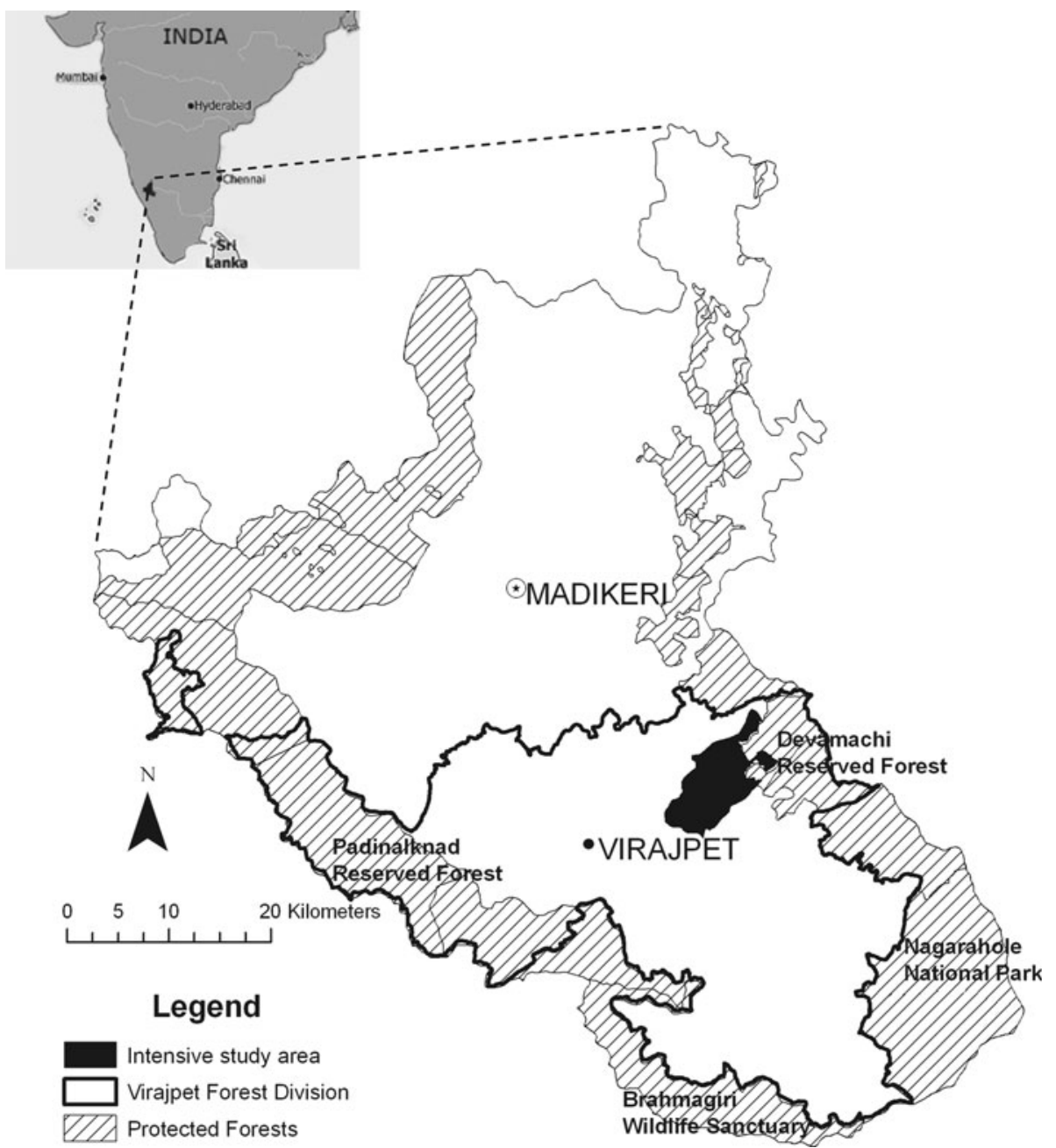

are planted during the June-September monsoons and lie fallow during the dry half of the year (December-May).

From 1977 to 2007, Kodagu lost 30\% of its forest cover whilst the area under coffee increased by $100 \%$ (Elouard and Guilmoto 2000; Garcia and others 2010), expanding predominantly into privately owned forests (Garcia and Pascal 2006). Forest area formally controlled by the Karnataka Forest Department (KFD) has remained largely intact. The district is divided into two KFD administrative units called divisions: Madikeri in the north and Virajpet in the south. Our study focused on the Virajpet Forest Division where the Rajiv Gandhi (Nagarhole) National Park (NPP) is located (Fig. 2). The adjacent district of Hunsur hosts the Wildlife Division in charge of the National Park.

\section{Data Collection}

\section{Landscape Level Spatial and Temporal Patterns}

We collected records from the KFD that detail crop damage by elephants and farmers' compensation claims between 1996 and 2007 (i.e., corresponding to the 12 fiscal years between 1996/1997 and 2007/2008). The records were obtained from the Deputy Conservator of Forests (DCF) offices in Virajpet, Madikeri and Hunsur. We were provided with the original records, not secondary reports or compilations for internal communication, for the relevant villages for these 12 years. We examined 3,240 records in all: 2,420 from Virajpet, 14 from Madikeri and 806 from Hunsur. The archives of the Hunsur Wildlife Division were incomplete and villages adjoining Nagarhole National Park (NNP) and Brahmagiri Wildlife Sanctuary (BWS) in southern Kodagu were missing data. The intensity of conflict reported in these villages underestimate the real extent of the problem.

Annual data obtained from the KFD were translated from the local language, Kannada, entered into a database and incorporated into a GIS to analyse spatial and temporal patterns of conflict in and around Virajpet Division. The 501 records obtained for 2006/2007 contained detailed descriptions of crop damage recorded by month. We used these data for seasonal analysis. 
Data on the number of rainy days and total annual rainfall for 1996-2007 were obtained from the Directorate of Economics and Statistics, Bangalore, Karnataka. We used data collected at 13 monitoring stations that are geographically dispersed within and on the periphery of Virajpet Division: Ammathi, Dubari, Makuta, Maldare, Mundrote, Nagarhole, Naladi, Napoklu, Ponnampet, Siddapura, Srimangala, Thithimathi and Virajpet. The annual data on rainfall $(\mathrm{mm})$ and the number of rainy days were averaged across the 13 locations and used to test for correlations with annual crop damage.

\section{Stakeholder Perceptions}

During May-July 2007, we conducted semi-structured interviews with estate owners and managers, forest watchers, workers and tribal inhabitants, and local experts to elicit local perceptions on the causes of HEC, crop damage, locally developed coping strategies and the role of stakeholders. The objective was to capture the diversity of views, not to produce a quantitative assessment. Eighteen formal interviews were carried out in English, wherever possible, or in Kannada with the assistance of a translator. The first five interviewees were identified from KFD records of compensation claims. Additional interviews were added through snowball sampling (Bernard 2006), each interviewee asked to make recommendations and provide contact information for others who might be interested in participating in the research project. Enlisting the five initial respondents without introductions through social networks, thus exploring five parallel social networks, counteracted the bias that this kind of purposive sampling relying on social networks for data collection may introduce (Johnston 2005). Formal interviews stopped after reaching saturation (Strauss and Corbin 1998), when no new topics or relationships among topics were coming to light. Premature closure (Wilson and Hutchinson 1990) was avoided through triangulation with existing reports (Nath and Sukumar 1998; Kulkarni and others 2007; Bhoominathan and others 2008) and continued interactions with landless residents, smallholders and well-to-do planters, as well as various government officials working in the district (Garcia and others 2010).

Interviews lasted for 1-2 hours and were systematically followed by a survey of the estate for elephant traces and damage, as an additional step of triangulation. Based on the interviews, we constructed a problem tree (European Commission 2004).

\section{Estate-Level HEC Drivers}

During February-April 2008 we randomly selected 20 coffee estates for intensive study, along a transect perpendicular to the forest boundary and extending up to the middle of the district (see Figs. 2, 3). The transect was 10-11 km long and located in an area of high conflict. Habitat variables that might be related to elephant visits were identified based on the interviews. Canopy cover, grass biomass, canopy species composition and tree density measurements were recorded in the field from ten randomly located sampling points per estate. At each random point, five measurement points were defined, one on the point itself and four others positioned $10 \mathrm{~m}$ to the north, south, east, and west. Canopy cover was estimated with a concave spherical densiometer; and biomass estimates were obtained by collecting undergrowth samples from plots of $0.25 \mathrm{~m}^{2}$ at each of the five measurement points. Canopy species composition and tree density were recorded up to a $10 \mathrm{~m}$ radius from the centre point. The species that showed repeated elephant damage in KFD and interview data, such as Erythrina subumbrans (dadap), Artocarpus heterophyllus (jackfruit), Areca catechu (arecanut), Musa paradisiaca (banana) and Cocos nucifera (coconut) were classified as 'preferred trees'.

Additional habitat variables such as estate area, distance to the nearest forest, area under rice cultivation and number of water bodies, were obtained from GPS (Trimble: Geoxm, 2005 series) markings and measured with IRSp6 images with $23.5 \mathrm{~m}$ resolution, using geographic information system software, ArcGis 9.1. Area under rice cultivation and number of water bodies were calculated using an area that included the estate as well as a $500 \mathrm{~m}$ buffer around the estate boundary (Fig. 3). The frequency and nature of elephant visits (number of elephants, time of visit, time of stay, damage caused) and details of the selected estates (crops grown, management, nearest forest, mitigation methods adopted) were collected by means of questionnaires. The frequency of elephant visits was measured by asking the number of months per year in which elephants visited the estates. Although coarse, a pilot questionnaire suggested this indicator of elephant visits to the plantations since farmers did not keep records nor could they accurately recall how often elephants entered their estates in a given year.

\section{Coffee Berry Consumption}

During February-April 2008 we also studied elephant consumption of ripe coffee berries by recording the location of all dung piles observed (209) and counting the coffee seed cotyledons within them (see Fig. 4). The two seed cotyledons per berry are separated from each other after passing through the elephant's gut. A cluster of seeds on a branch usually contains $20-30$ coffee berries. We thus classified the dung piles into three classes according to the number of coffee seed cotyledons present (1) zero cotyledons, (2) 1-50 cotyledons per dung pile representing 


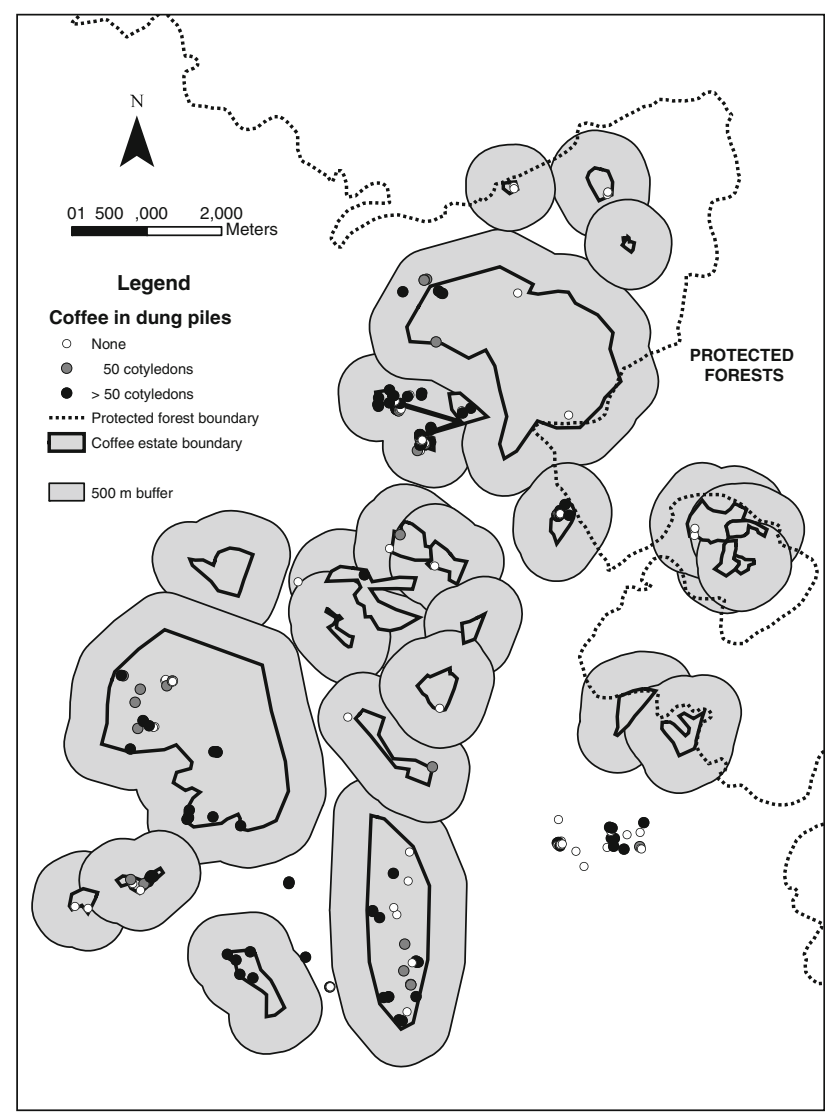

Fig. 3 Locations of the 20 estates used for intensive study with dung pile locations used for assessing elephant coffee consumption. Solid lines mark individual estate boundaries with some estates consisting of 2-3 separate patches of land. Dashed lines mark state-controlled forest boundaries. The shaded buffer areas indicate the $500 \mathrm{~m}$ boundaries used to determine the number of rice paddies and water tanks of each estate. Black circles represent dung piles containing $>50$ coffee seed cotyledons; grey circles 50 or fewer cotyledons; unshaded circles 0 cotyledons

involuntary ingestion of berries and (3) $>50$ cotyledons per dung pile representing voluntary consumption of coffee.

Dung bolus diameter was used as a proxy for age class (Jachmann and Bell 1984; Morrison and others 2005). An elephant dung pile consists of $5.6 \pm 1.45$ boluses, each of which is roughly cylindrical in shape (Fig. 4) with average diameters varying from $6 \mathrm{~cm}$ to $18 \mathrm{~cm}$ for the Indian elephant, depending on the individual's age and sex (Jachmann and Bell 1984). Of the 209 dung piles observed, 147 could be measured for bolus diameter by averaging the mean diameter along the longest and shortest width axes for three cylindrical boluses per dung pile (Morrison and others 2005). The remaining 62 dung piles could not be measured and classified by age due to damage to the boluses. We grouped elephant dung piles into two age classes: juveniles and adults. Dung piles with an average bolus diameter up to $10 \mathrm{~cm}$ were classed as coming from juveniles (Jachmann and Bell 1984; Sukumar 1989; Reilly

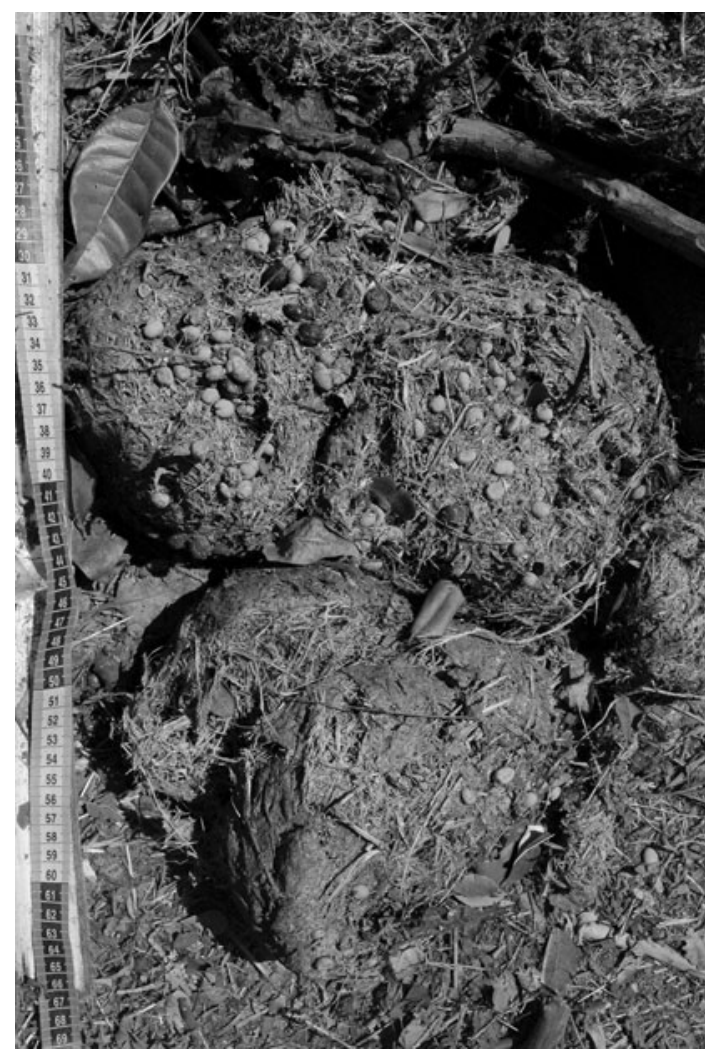

Fig. 4 Elephant dung containing coffee seeds ( $>50$ cotyledons). The cylindrical boluses are evident

2002). The age distribution obtained with this size classification was not significantly different $\left(\chi^{2}=0.8622, N=\right.$ $147, \mathrm{df}=1, P=0.3531)$ from the proportions of juvenile to adult elephants in the KFD's 2005 elephant census (KFD, unpublished data).

\section{Statistical Analysis}

We used Spearman rank correlation (Hoare 1999; Sitati and others 2003) to check for linear relationships between crop damage and years. We also checked for correlations between crop damage cases and two rainfall variables: quantity of rainfall and number of rainy days per year. As some crops, such as coffee, may be dependent on rainfall during the previous year, we also checked for relationships with a time lag of 1 year (i.e., current year's crop damage values correlated with previous year's rainfall values).

Data on estate-level drivers were averaged across the different points sampled per estate before analysis. We first used Spearman rank correlation to check for univariate relationships between the number of months per year in which elephants visited estates and the ten habitat variables. We then explored the link to multiple habitat variables with a generalised linear model (GLM) with the logit link for binomially distributed errors. We started with an 
initial model with six variables to reduce collinearity (critical $R_{\mathrm{S}}=0.447$ for a 2 -tailed test, $\alpha=0.05, N=20$ ): canopy density, and non-normal variables transformed as follows: $\log$ of estate area, and square roots of distance to forest, paddy fields nearby, fruit tree density and grass biomass. We operated a backward selection based on the Akaike Information Criterion. We also carried out principal components analysis using the ten estate variables together with the transformations listed above.

Analyses were carried out using SPSS for Windows (version 13) and R (version 2.9.1).

\section{Results}

Spatial and Temporal Patterns

The number of crop damage cases varied widely from year to year between 1996 and 2007 (Fig. 5). The change in number of cases over time was not linear, but there was a substantial increase during 2005-2007, leading to an overall positive correlation between number of crop damage cases and the passing of time (Spearman rank correlation coefficient $R_{\mathrm{S}}=0.70, P=0.015$ ). We discuss the validity of this result below. There was a positive trend in this relationship but no significant correlation between the number of crop damage cases and quantity of rainfall $\left(R_{\mathrm{s}}=\right.$ $0.48, P=0.12)$ or number of rainy days $\left(R_{\mathrm{s}}=0.49\right.$, $P=0.11$; although this was significant with the Pearson correlation coefficient, $R=0.60, P=0.04$ ) for the 12 years studied. The use of a time lag in rainfall data did not strengthen the correlation.

The mean annual number of crop damage incidents when plotted on a map of Virajpet Division showed varying intensity of conflict across villages (Fig. 6). The region of highest conflict was the northeastern part of the

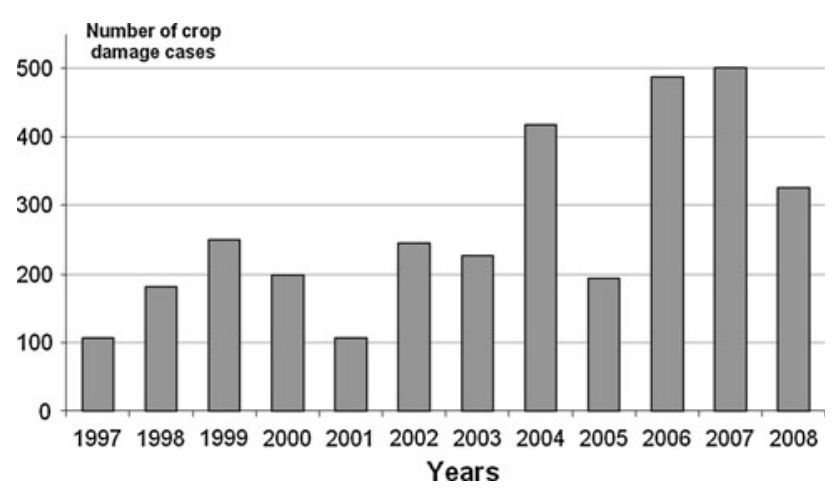

Fig. 5 Temporal trend in the annual number of crop damage incidents in Virajpet Division, between 1996/1997 and 2007/2008 $(n=3,240$ reports $)$

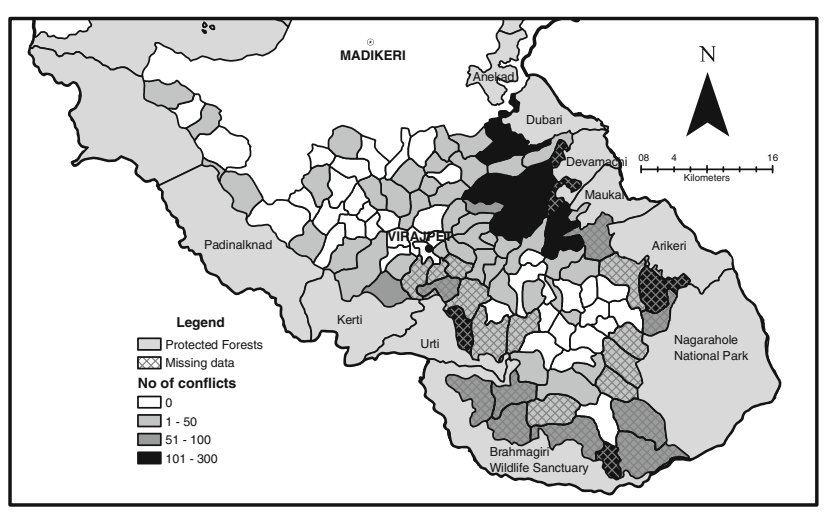

Fig. 6 Spatial map of HEC in Virajpet Division, showing total incidents registered per village during the 12 years from 1996/1997 to $2007 / 2008$ ( $n=3,240$ reports)

division. Conflicts also occurred along all forest boundaries. It is possible that some of the villages adjoining Nagarhole National Park and Brahmagiri Wildlife Sanctuary in southern Kodagu suffer from higher intensity of conflict than are apparent in our map due to a few missing datasets, as described under 'Data collection' above. Highconflict areas extend in a band across the division from east to west. A number of villages seemed to experience low intensity of conflict even though they were adjacent to high-conflict areas.

There were no registered crop damage incidents from settlements located inside the state-controlled forest belt. The inhabitants of these settlements lacked legal land rights prior to the enforcement of the Forest Rights Act 2006 (31st December 2007). They were therefore ineligible for the compensation scheme. Any conflict experienced by these settlements has gone unreported and uncompensated.

\section{Seasonal Trend}

Crop damage due to elephant visits during 2006-2007 was highly seasonal (Fig. 7). The peak in compensation cases from June to August was primarily due to damage to coffee bushes, fruit trees and associated pepper vines, accounted for in the category 'Other crops'. During the second peak from November to December the damage was concentrated in rice paddies. Another peak in the number of reports of damage to fruit trees and coffee bushes occurred in February during the coffee-ripening season.

Perennial crops including coconut, areca nut and banana exhibited bimodal annual patterns in crop damage whereas damage to the seasonal rice crop peaked exclusively at the time of ripening. Coffee showed a bimodal pattern of damage, similar to the other perennial crops. 


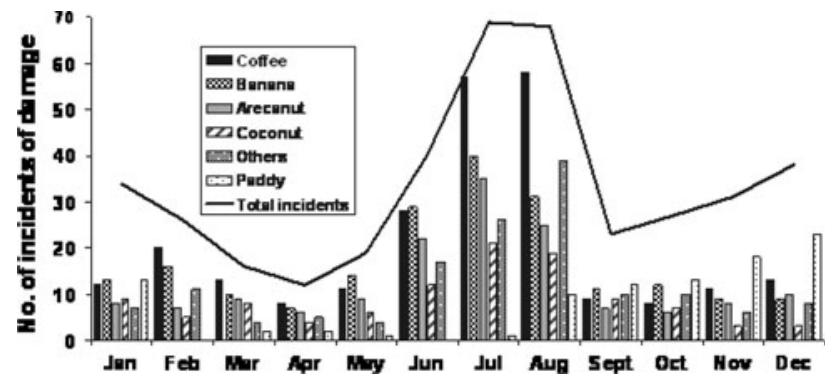

Fig. 7 Temporal distribution of raids on different edible crops based on reports filed by farmers in Virajpet Division during 2006/2007. The distribution shows seasonal patterns. The crops that were damaged most often are represented individually. The category 'others' includes the less frequently damaged orange, cardamom, ginger and pepper. Data come from damage reports filed by affected farmers ( 1 report $=1$ incident of damage). A single report can mention several crops. The black line indicates the total number of incidents reported

\section{Stakeholder Perceptions}

Data from interviews suggest that elephant visits to estates are an old phenomenon. Still, half of the respondents claimed that HEC had increased in Virajpet since 1997. For $16 \%$ of them, the problem was only 5 years old. This significant portion suggests that newer areas were becoming part of the conflict zone, leading to an increase in the spread and intensity of HEC.

According to the respondents, the rise in HEC stems from four reasons: (1) the forest has insufficient resources to sustain the large elephant population; (2) elephants are exhibiting new behavioural patterns; (3) their original habitat has experienced degradation; and (4) the local elephant population has increased (Fig. 8).

Interviews highlighted discontent from all residents, especially farmers, as reported in previous studies (Kulkarni and others 2007), with the KFD's attitude towards conflict mitigation. Some farmers acknowledged the KFD lacked staff and infrastructure to deal adequately with the problem (six respondents), but also blamed the institution for inadequate maintenance of the solar fences (SF) and elephant-proof trenches (EPT; ten respondents). They also mentioned the lack of fast or adequate help to the affected farmers (nine respondents). The respondents felt that the KFD lacked transparency in its decision making (seven respondents) and experienced no effective dialogue with the agency (two respondents).

\section{Estate-Level HEC Drivers}

We found moderately strong univariate correlations of elephant visits with estate area and water availability $\left(R_{\mathrm{S}}=0.67\right.$ and 0.63 , respectively, $P<0.005$; Table 1$)$, and a negative correlation with tree density $\left(R_{\mathrm{S}}=-0.52\right.$, $P<0.05$ ). Less strong positive relationships also were observed with paddy availability and distance to the nearest forest $\left(R_{\mathrm{S}}=0.43\right.$ and 0.38 , respectively, $\left.P<0.1\right)$.

Stepwise deletion of factors from the initial model containing six variables, resulted in a final parsimonious model with four statistically significant variables: estate area (coefficient: $1.11, P<0.0001$ ), distance from the forest (coefficient: $0.03, P<0.0005$ ), fruit tree density (coefficient: $0.24, P=0.023$ ) and grass biomass (coefficient: -0.32 ,
Fig. 8 Problem tree on the question: why do elephants enter the estates? Causes are classified as: (1) resource allocation at landscape level in light grey, (2) stakeholder coordination and public policies in dark grey, (3) spatially driven processes in white and (4) elephant behavioural traits, dotted

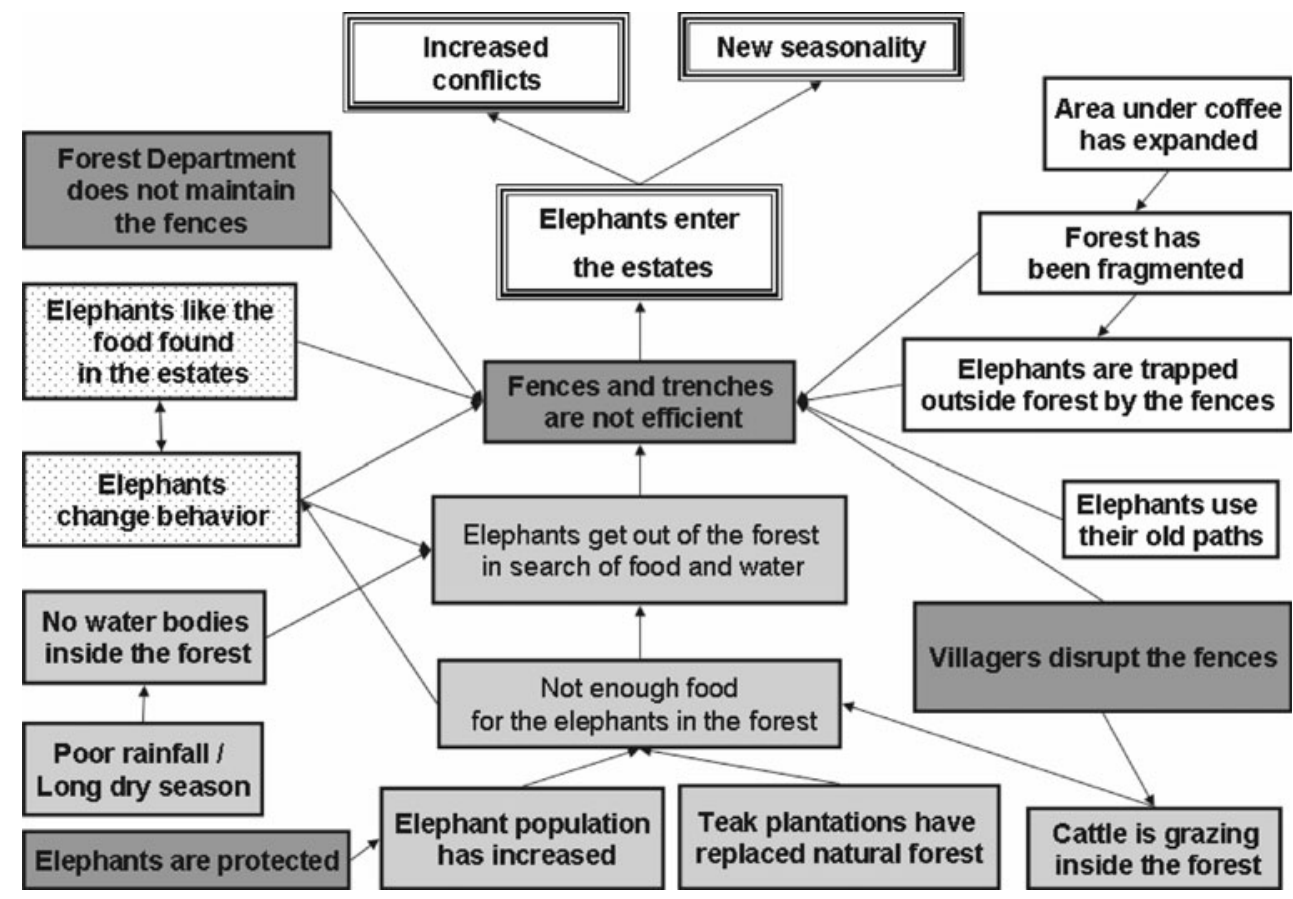


Table 1 Spearman rank correlation coefficients $\left(R_{\mathrm{s}}\right)$ between elephant visits per year to an estate and the estate variables (arranged in decreasing order of significance)

\begin{tabular}{lcc}
\hline Estate variable & $\begin{array}{l}\text { Correlation with } \\
\text { elephant visits }\left(R_{\mathrm{s})}\right.\end{array}$ & $P$-value \\
\hline Estate area & 0.67 & 0.001 \\
Water availability & 0.63 & 0.003 \\
Tree density & -0.52 & 0.018 \\
Paddy availability & 0.43 & 0.057 \\
Distance to forest & 0.38 & 0.098 \\
Preferred tree density & -0.37 & 0.105 \\
Erythrina subumbrans density & -0.30 & 0.193 \\
Fruit tree density & -0.19 & 0.424 \\
Canopy density & -0.03 & 0.915 \\
Grass biomass & 0.02 & 0.930 \\
\hline
\end{tabular}

Table 2 Slope coefficients for a generalised linear model with binomial distribution of errors of elephant visitation to estates modelled as a function of four estate variables

\begin{tabular}{lccr}
\hline Variable & $\begin{array}{l}\text { Slope } \\
\text { coefficient }\end{array}$ & $\begin{array}{l}\text { Standard } \\
\text { error }\end{array}$ & $P$-value \\
\hline Log of estate area & 1.106 & 0.187 & $<0.0001$ \\
Square root of distance to forest & 0.028 & 0.008 & 0.0003 \\
Square root of fruit tree density & -0.241 & 0.106 & 0.0229 \\
Square root of grass biomass & -0.319 & 0.147 & 0.0300 \\
\hline
\end{tabular}

Results presented correspond to the most parsimonious model, with the lowest Akaike Information Criterion value

$P=0.030$, Table 2). Goodness of fit of the final model, obtained by subtracting the proportion due to residual deviance from 1 , was 0.545 . However, errors were overdispersed, suggesting we may have missed influential predictor variables, or the sample size of 20 estates may have been too low for appropriate estimation. Marginally significant variables should therefore be considered with caution.

Principal component analysis with all ten variables produced a major axis explaining $35 \%$ of variation, which was characterised by estate area, water availability and distance to forest in one direction, versus preferred trees, tree density and Erythrina density in the opposite direction. Area is significantly correlated with water and distance to forest whereas tree density is significantly correlated with preferred trees and Erythrina density. We interpret this to mean that the main axis shows an area effect in one direction and a tree density effect in the opposite direction. The second axis, explaining 19\% of variation, was associated with canopy cover and Erythrina density in one direction, suggesting a cover or visibility effect, versus fruit tree density, grass biomass and total tree density in the

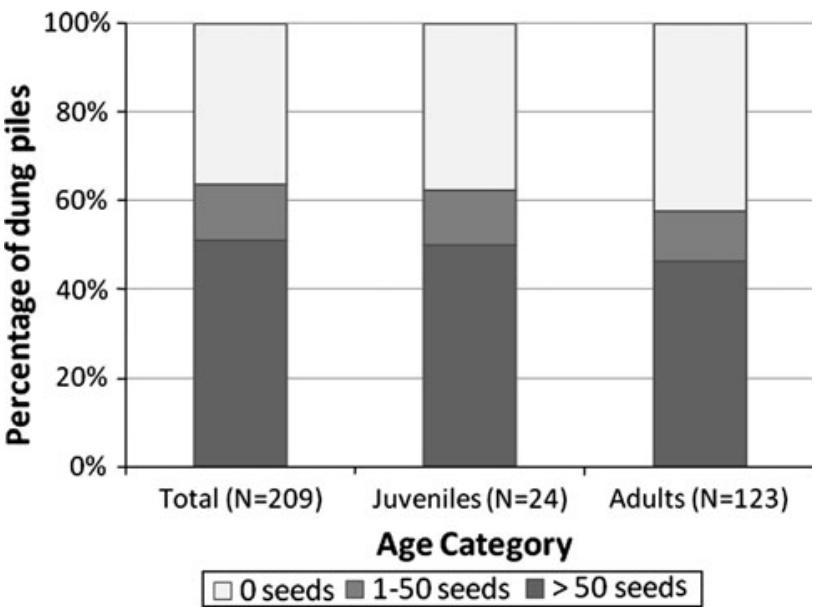

Fig. 9 Proportions of elephant dung piles encountered in the study area that contained coffee seeds cotyledons $[0$ cotyledons (white), 1-50 cotyledons (light grey), and $>50$ cotyledons (dark grey)]. Dung piles were classified by average bolus diameter into juvenile $(n=24)$ or adult $(n=123)$. Damaged piles $(n=62)$ could not be classified, but are integrated in the total

opposite direction. These were not correlated with each other, but may be related to foraging.

\section{Coffee Berry Consumption}

We found a high proportion (0.64) of dung piles contained coffee seeds. More than $50 \%$ of the total sample had $>50$ coffee cotyledons (Fig. 4), suggesting ripe coffee berries were part of the diet of the elephants in the area. We did not find significant differences between age groups $\left(\chi^{2}=0.1887, \mathrm{df}=1, P>0.66\right)$ suggesting adults and juveniles ingest similar amounts of coffee (Fig. 9).

\section{Discussion}

\section{Crop Damage Patterns}

Human-elephant conflict incidents reported in Virajpet Division has increased over the years, though much of the observed increase can statistically be accounted for by the abrupt increase in incidents in 2005-2007). However; the fewer incidents in 2007/2008 and high interannual variability indicate that the increase in conflict is not a steady upward trend but rather a series of discrete periodic increments, as seen in the years 1998/1999, 2003/2004 and $2005 / 2007$. This result differs from those of previous studies (Nath and Sukumar 1998; Kulkarni and others 2007) which found no significant increase in the number of incidents per year between 1992 and 2004. Our finding that there is a significant upward trend in crop raiding incidents per year in Virajpet since 2005 suggests worsening conflict 
in the district, which has considerable implications for land-use management in the division.

Rainfall is a plausible candidate for explaining some of the interannual variability in crop raiding. Our analysis, although coarse given the large spatial scale and few data points available, suggests that years with more rainy days are likely to be associated with greater raiding. Further studies at finer spatial scales are required to understand exactly how rainfall may influence crop raiding by elephants.

The conflict map shows a mosaic of high and low conflict areas in Virajpet Division. Villages lying next to the Devamachi RF on the eastern part of the division report the highest conflict intensity. According to stakeholder perceptions (Fig. 8), the teak (Tectona grandis) plantations and scarce water sources in the dry deciduous forest are driving elephants out of the forest. Most of the teak plantations in Kodagu are ageing, due to a ban on tree felling introduced in the State in 1990. Elephants in Tanzania, in comparison, use young teak plantations $(<6$ years old) to a greater extent than older stands (Bonnington and others 2009). We assume that elephants in our division favour food resources in the coffee plantations over those found in older teak, driving them out of the forest.

High intensity of wildlife-human conflict in areas adjoining forests have been described elsewhere (Naughton-Treves 1998), and suggest that wild animals use the cover and relative protection of thicker forest growth to make short forays into crop and nutrient-rich humanmodified habitats (Nyhus and others 2000). Large corporate estates in this area, with abundant resources, water tanks maintained for irrigation and native tree cover, remain lush and green even during dry months and thereby attractive to elephants.

The central band of higher conflict between the east and west forest belts, with adjacent areas showing zero conflict, suggests a corridor of elephant movement and is congruent with previous studies (Nath and Sukumar 1998). Annual crop damage maps showed a continuous band of conflict stretching from east to west across the centre of the division in at least three of the 12 years examined (data not shown here). This suggests a seasonal, though not systematic, migration between the eastern and western sides of the district through this route, following the southern ridge of the Kavery river watershed. Other studies (Osborn and Parker 2003; Sitati and others 2003) suggest similar associations between migratory routes and crop raiding.

The annual raiding peaks we documented accord with previous studies (Nath and Sukumar 1998; Kulkarni and others 2007). In examining the reasons for these peaks in damage, we identified three crop raiding patterns. Perennial fruit crops like banana, areca nut and coconut are unlikely to be the main cause of increased elephant visits during a specific season because they ripen throughout the year. However, the raiding peak in June-August coincides with the fruiting seasons of jackfruit (May-September) and mango (May-August), two species that, when ripe, are excessively damaged by elephants, according to local reports. Ripe jackfruits are strong-smelling, large and conspicuous, and are probably the main seasonal lure. Damage done to coffee, pepper and other fruit trees at this time may largely be coincidental as these crops are all interplanted. An analogous situation was reported from villages around Kibale National Park, Uganda, where peaks in raiding of perennial banana crops by forest-dwelling primates were driven by seasonal shortages in their more highly favoured wild fruit species (Naughton-Treves and others 1998).

The second peak between November and December can be explained by the availability of rice. The spatial segregation between rice paddies and coffee estates explains the relatively low damage to coffee during this time of year.

Finally, the third peak in February coincides with the coffee ripening season suggesting that coffee itself is acting as a seasonal attractant when ripe. This is substantiated by our results on presence of coffee seeds in the dung piles, as discussed below.

\section{Drivers of HEC}

According to stakeholders we interviewed, HEC has become a year-round phenomenon unlike in earlier times. The elephants' high sociability, intelligence, periods of musth and migration, flexibility in their diet and behaviour in response to disturbance or threat and an optimal foraging strategy (Sukumar 1990; Campos-Arciez 2006) has contributed to the spatial and temporal spread of HEC in Virajpet.

The area under coffee cultivation has doubled in Kodagu district over the last 30 years (Garcia and others 2007). The landscape mosaic of the coffee agroforestry system in the district offers a variety of highly palatable, densely packed and easily accessible resources including fruit trees, paddy, grass, and water. Perennial water bodies inside coffee estates, not found in state-controlled forests, and the use of fertilisers result in better plant growth even during the dry season. Further changes in land use and degradation due to dams and forest fires have caused habitat fragmentation and subsequent disruption of elephant migratory routes. All these factors were reiterated in stakeholder perceptions during this study, as well as in earlier studies in the district (Nath and Sukumar 1998; Kulkarni and others 2007).

At the estate level, the size of the estate was the most important factor associated with frequency of elephant visits. This could be interpreted as a habitat neutral result: Elephants do not prefer any particular quality of estate, but 
occur more frequently in larger estates merely by chance. The positive correlation between estate size and resources such as water $\left(R_{\mathrm{S}}=0.68\right)$ and rice paddies $\left(R_{\mathrm{s}}=0.37\right)$ reinforces this link. This interpretation is supported by the principal component analysis ordination results, which suggest that area- and movement-related variables were of primary importance whereas foraging variables were of secondary importance.

Another factor to consider is that large corporate estates have a low human population density. This means that large parts remain undisturbed for days or weeks and thus potentially serve as refuge areas for elephants outside the protected forests. Similarly, Sitati and others (2005) report increased elephant raids on large farms in Kenya, which tended to be less well guarded than small farms there.

Two unexpected relationships identified during this study were the negative correlation of elephant visits with tree density, and the positive correlation with distance from the forest. Tree density was likewise negatively related to estate size $\left(R_{\mathrm{s}}=-0.54\right)$, hence the main driver of this relationship may be estate size. In the case of distance from the forest, a possible explanation is that some large estates situated $5-10 \mathrm{~km}$ from the forest may have served as temporary refuges while elephants raid neighbouring estates; they did not need to travel back for the protection of the forests after nightly raids. Nath and Sukumar (1998) suggest that forest patches in the centre of the district also provide daytime refuge for small groups of elephants migrating between the district's eastern and western forests. In this context, it would be interesting to find out if large estates are more likely to contain similar forest patches or semi-wild blocks that serve a similar purpose.

Rice is a strong seasonal attractant during the ripening season. Jackfruit alone does not show a strong correlation, but jackfruit along with other trees could be attracting elephants (if considered significant at $P=0.10$ ).

\section{Coffee Berry Consumption}

Previous studies (Nath and Sukumar 1998; Kulkarni and others 2007) did not report that elephants were seeking out coffee berries. The occurrence of substantial numbers of coffee seeds in $>50 \%$ of dung piles (Fig. 9) indicates that they now are. Juvenile and adult elephants invested similar amounts of time feeding on ripe coffee berries while inside the estates.

Coffee berries in Kodagu ripen between December and February, earlier for Arabica, later for Robusta. Coupled with the peak of damage to coffee bushes in February, the presence of seeds in the dung indicates that coffee itself is becoming an attractant, creating a new seasonal pattern.

However, we cannot say if this represents deviant behaviour of a few individual elephants, a segment of the population or the entire local population. The high defecation rate in elephants, 17 droppings per elephant per day on average (Jachmann and Bell 1984; Ekobo 1995; Theuerkauf and Ellenberg 2000), could imply that the dung piles sampled represent only a few individuals. However, our systematic sampling of 209 dung piles was reasonably extensive: It lasted 3 months, included different age classes and covered 5,600 ha within more than half of the estates in the study site (Fig. 3). This strengthens the assumption that several individuals were represented by the sample. DNA analysis of the dung would answer this question.

It is possible that coffee-eating behaviour can be attributed to a segment rather than the entire local population. A small proportion of individuals within a population can be the cause of HEC (Hoare 1999; Hoare 2001b; Nelson and others 2003). Even if currently confined to a few individuals, this novel behaviour could rapidly spread through the local population via cultural transmission and learning (Thouless and Sakwa 1995). Were that to happen, it could greatly compound an already severe conflict situation due to the high economic value of coffee.

\section{Indicator Bias}

We used incident reports filed by individual farmers seeking compensation from the Forest Department for damage that elephants caused to reflect the actual intensity of HEC in the district. Using this indicator presents several difficulties.

We expect the reports on casualties to be reliable. They involve forensics and become public through the local media. We assume these numbers to be an exact measure of the actual number of casualties incurred through humanelephant encounters.

Economic quantification based on the amount paid for compensation is however not a good estimator of the seriousness of the conflict. In the Bhadra Wildlife Sanctuary, located $150 \mathrm{~km}$ north of our study area, compensations paid by the Karnataka Forest Department covered only $5 \%$ of the value of the crops lost to elephants (Madhusudan 2003). Without means for cross-validating the extent of economic loss incurred by the local communities using first-hand data at district level, we chose to use the number of compensation cases rather than the amount of monetary transactions as a better indicator of the intensity of conflict.

This indicator also has potential biases. Villagers may not consistently file incident reports and forest officials may not record all complaints. We received consistent complaints from our respondents and other stakeholders about inefficient procedures (Laval 2008). People are discouraged from reporting damage for several reasons: strained relationships with the forest official in charge; the 
inconvenience and cost of travelling to the Forest Department office, that sometimes include the loss of a days' wage; the time lag between reporting and receiving compensation; and the paucity of compensation. This bias also leads to an underestimation of the real extent of HEC based on administrative data.

The different levels of reporting across villages indicates a second possible bias that can affect the spatial patterns described here. Different villages, with different foresters in charge, could have different perception of the severity of the problem and different degrees of access to the Forest Department for reporting the damage. The map (Fig. 6) therefore shows occurrence patterns with a bias due to the discrepancies in the way people perceive the damage and report. The incomplete archives in Hunsur Wildlife Division add to the spatial bias because the affected villages exhibit lower intensity of conflict than actually occurred. Some factors nonetheless mitigate these discrepancies and homogenise perceptions of HEC across villages: news and information communicated through social networks such as planter's clubs, articles in the local media that further disseminates information, and the single official, the District Conservator of Forests, who oversees procedures across the division.

In conclusion, the original reports obtained from the Forest Department archives remain at present the only and best available data source for estimating the intensity of HEC in the district, despite these biases that tend to underestimate its real extent. True occurrence maps at the district level would require extensive resources in time and manpower for a marginal gain that would not obviously offset the costs, given the existence of this indicator.

\section{HEC in Kodagu as a Wicked Problem}

We document a trend of increasing conflict, with new seasonal patterns and new elephant behaviour that will affect local stakeholders negatively in the years to come. In response to these trends in the district, different mitigation strategies have been tried over the past decade. Deterrent and control methods (translocation, chilli powder, solar electric-shock fences, elephant-proof trenches and scaring squads) have met with limited and temporary success, for technical reasons, lack of manpower and/or designated funding, lack of coordination between actors, or the adaptability of the elephants themselves (Nath and Sukumar 1998; Kulkarni and others 2007; Bhoominathan and others 2008; Laval 2008). These relative failures coupled with discontent regarding the compensation scheme have directly translated into stakeholder distrust which is liable to hinder any future strategy proposed. Some respondents acknowledged that no solution would solve the problem; others were keen to explore new alternatives such as setting up of private fences, chilli smoke or radio collaring studies. Most respondents were still waiting for a silver bullet.

Taking all these elements into consideration, we suggest that stakeholders in Kodagu would gain by considering HEC as a 'wicked' problem (Horst-Rittel and Webber 1973). Wicked problems have no definitive formulation, no stopping rule, and no test for a solution. Final resolutions are unlikely and each problem is unique and defies classification (Ludwig 2001).

In the case we studied, the multiple stakeholders did not share a common definition of the problem nor its causes. Farmers blame the teak plantations established by the Forest Department. Landless villagers living in the forest, who have fewer problems with elephants raiding their crops, point to the fences preventing them from accessing forest resources. Forest Department officials see intrusions into state-controlled forests as the problem, and sometimes even consider the elephant threat as a deterrent.

Each solution tried to date has been more or less acceptable to different stakeholders rather than objectively good or bad. Solar electric shock fences may have reduced elephant intrusions, but they have also prevented cattle from grazing in the forest, benefiting some stakeholders but inconveniencing others. They also require funding and a labour force to maintain them. When the Forest Department recently launched a capture and relocation programme, it lost animals due to stress or misestimated tranquiliser dosages (Gandhi 2009). In short, no amount of technical expertise is likely to solve this problem. Each solution will entail costs and lead to unexpected consequences, and may even worsen the problem. The solving process will stop only when the flow of resources dries up or when the society decides it is no longer an issue (Conklin 2006).

Applying this concept, and in agreement with Conover (2002), we propose that resolving HEC in Kodagu requires a combination of deterrent, compensating and toleranceraising strategies with better stakeholder involvement. The decision makers need to develop an integrated approach, sifting through the multitude of potential solutions to find a combination of techniques that will reduce damage to tolerable levels. None of these techniques is new. Village Eco-Development Committees could be more actively involved in maintaining the solar electric shock fences or streamlining the compensation process. A crop insurance scheme could be more efficient than the current compensation system if farmers were involved in developing the scheme's modalities. The conflict map (Fig. 6) could help frame priority intervention areas or devise insurance rates, with costs commensurate with farmers' threat perception and risk aversion. A landscape-level labelling (Ghazoul and others 2009) or elephant-friendly coffee label, (Aane kaapi, 'elephant's coffee' in Kannada) similar to the 
bird-friendly coffee label of the Smithsonian Institute, could help raise the tolerance level within the local population. This scheme could build upon the iconic value elephants have at local and international levels. The fact that elephants have started feeding on coffee could even be used to attract consumer attention. Such a scheme could either secure a premium price for products marketed with this label or secure market access. If farmers obtain a tangible benefit from the presence of elephants in their estates, the problem may cease to be perceived so negatively.

Rather than being offered further examples of possibly effective coping strategies like these, we argue that stakeholders in Kodagu need to be aware of the true nature of the problem they face, lest they continue to try to 'tame' it (Conklin 2006), grow increasingly disheartened as failures accumulate and mistrust between stakeholders becomes entrenched.

\section{Conclusion}

The Asian elephant in Kodagu provides a case study in which ecological, economical, sociological and religious factors merge to create a complex, deeply felt and potentially harmful combination for all involved parties. Recognising the nature of the problem at hand, conflict mitigation calls for a combination of adaptive management strategies based on three elements: (1) the ecology and behaviour of elephants, (2) site-specific spatial and temporal determinants of conflict rather than density based indicators such as the number of people and elephants living together (Barnes and others 1995; Hoare 1999; Hoare and Du Toit 1999) and (3) the human sociopolitical and economic environments (Thouless and Sakwa 1995; O'Connell-Rodwell and others 2000; Inskip and Zimmermann 2009). The problem will only be solved when the local society decides that the perceived benefits derived from the presence of the elephants outweigh the perceived damage they cause. Better transparency in decision making and solutions that increase public tolerance of elephants through direct benefits are thus needed.

\footnotetext{
Acknowledgments This paper was carried out with the financial support of the French Agence Nationale de la Recherche under the Programme Agriculture et Développement Durable (ANR-06-PADD014, POPULAR), and of the European Commission under the Program on Environment in Developing Countries project (CAFNETEuropaid/ENV/2006/114-382/TPS). We thank the Karnataka Forest Department, Tata Coffee Limited, and individual farmers for giving us necessary permissions and extending their cooperation. We thank the interviewees and field assistants for their cooperation and support during fieldwork and Pascal Douard for GIS support, Jenu Kalla for collecting and typing Forest Department records, R. Jayapalan for preparing the rainfall data and Edith Johnson for the edition of the revised manuscript.
}

\section{References}

Barnes RFW (1996) The conflict between humans and elephants in the central African forests. Mammal Review 26:67-80

Barnes RFW, Blom A, Alers MPT, Barnes KL (1995) An estimate of the numbers of forest elephants in Gabon. Journal of Tropical Ecology 11:27-37

Bernard HR (2006) Research methods in anthropology: qualitative and quantitative approaches, 4th edn. Altamira Press, Walnut Creek, p 824

Bhoominathan D, Mohanraj N, Aziz T, Desai A (2008) Humanelephant conflict in Somwarpet Subdivision (Madikeri Forest Division), final report. WWF-India, Madikeri, India, p 52

Bonnington C, Weaver D, Fanning E (2009) The use of teak (Tectona grandis) plantations by large mammals in the Kilombero Valley, southern Tanzania. African Journal of Ecology 47:138-145

Campos-Arciez A (2006) Temporal and spatial patterns in the occurrence of human-elephant conflict incidents in southeastern Sri Lanka. Master's thesis, University of Tokyo, p 67

Census of India (2001) Basic data sheet, District Kodagu (25), Karnataka (29). http://www.censusindia.gov.in/Dist_File/datasheet2925.pdf.Accessed 12 Feb 2009

Coffee Board of India (2008) Database on coffee. Economic and Market Intelligence Unit, Bangalore, p 108

Conklin J (2006) Wicked problems and social complexity. In: Conklin J (ed) Dialogue mapping: building shared understanding of wicked problems. John Wiley \& Sons, West Sussex, pp 3-40

Conover MR (2002) Resolving human-wildlife conflicts: the science of wildlife damage management. Lewis Publishers, Washington, p 418

Ekobo A (1995) Elephants in the Lobeke Forest, Cameroon. Pachyderm 19:73-80

Elouard C, Guilmoto C (2000) Vegetation features in relation to biogeography. In: Ramakrishnan PS, Chandrashekara UM, Elouard C, Guilmoto CZ, Maikhuri RK, Rao KS, Sankar S, Saxena KG (eds) Mountain biodiversity land use dynamics and traditional ecological knowledge. UNESCO, Oxford and IBH Publishing, New Delhi, pp 25-42

European Commission (2004) Project cycle management guidelines. EuropAid Cooperation Office, Brussels, p 158

Gandhi V (2009) Only 3 vets at Forest Department's disposal. The Hindu, Karnataka Edition. 9 Jan 2009. http://www.hindu.com/ 2009/01/09/stories/2009010951010400.htm

Garcia C, Pascal J-P (2006) Sacred forests of Kodagu: ecological value and social role. In: Cederlöf G, Sivaramakrishnan K (eds) Ecological nationalisms: nature Livelihoods and identities in south Asia. University of Washington Press, Seattle and London, pp 199-229

Garcia C, Marie-Vivien D, Kushalappa CG, Chengappa PG, Nanaya KM (2007) Geographical indications and biodiversity in the Western Ghats, India: can labelling benefit producers and the environment in a mountain agroforestry landscape? Mountain Research and Development 27:206-210

Garcia C, Bhagwat SA, Ghazoul J, Nath CD, Nanaya KM, Kushalappa CG, Raghuramulu Y, Nasi R, Vaast P (2010) Biodiversity conservation in agricultural landscapes: challenges and opportunities of coffee agroforests in the Western Ghats, India. Conservation Biology 24:479-488

Ghazoul J, Garcia C, Kushalappa CG (2009) Landscape labelling: a concept for next-generation payment for ecosystem service schemes. Forest Ecology and Management 258:1889-1895

Hoare RE (1999) Determinants of human elephant conflict in a landuse mosaic. Journal of Applied Ecology 36:689-700

Hoare RE (2001a) A decision support system for managing humanelephant conflict situations in Africa. IUCN/SSC African Elephant Specialist Group, Nairobi, p 105 
Hoare RE (2001b) Management implications of new research on problem elephants. Pachyderm 30:44-49

Hoare RE, Du Toit JT (1999) Coexistence between people and elephants in African savannas. Conservation Biology 13:633-639

Horst-Rittel WJ, Webber MM (1973) Dilemmas in a general theory of planning. Policy Science 4:155-169

Inskip C, Zimmermann A (2009) Human-felid conflict: a review of patterns and priorities worldwide. Oryx 43:18-34

Jachmann H, Bell RHV (1984) The use of elephant droppings in assessing numbers, occupance and age structure: a refinement of the method. African Journal of Ecology 22:127-141

Johnston R (2005) Analytic culture in the US intelligence community: an ethnographic study. Center for the Study of Intelligence, Washington

Kemf E, Santiapillai C (2000) Asian elephants in the wild: a WWF species status report. WWF International, Switzerland, p 32

Kulkarni J, Mehta P, Bhoominathan D, Chaudhuri S (2007) A study of man-elephant conflict in Nagarhole National Park and surrounding areas of Kodagu district in Karnataka, India, Final report. Envirosearch, Pune, p 126

Laval M (2008) People, elephants and forests: collective action to manage an environmental wicked problem in Kodagu, Western Ghats. Agroparistech, Montpellier, France, p 154. http://www. ifpindia.org/ecrire/upload/reports/laval_2008.zip. Accessed 11 Sept 2008

Ludwig D (2001) The era of management Is over. Ecosystems 4: $758-764$

Madhusudan MD (2003) Living amidst large wildlife: livestock and crop depredation by large mammals in the interior villages of Bhadra Tiger Reserve, South India. Environmental Management 31:466-475

Madhusudan MD, Mishra C (2003) Why big, fierce animals are threatened: conserving large mammals in densely populated landscapes. In: Rangarajan M, Saberwal V (eds) Battles over nature: the science and politics of conservation in India. Permanent Black, New Delhi, pp 31-55

Morrison TA, Chiyo PI, Moss CJ, Alberts SC (2005) Measures of dung bolus size for known-age African elephants (Loxodonta africana): implications for age estimation. Journal of Zoology, London 266:89-94

Nath CD, Sukumar R (1998) Elephant-human conflict in Kodagu, southern India: distribution patterns, people's perceptions and mitigation methods. Asian Elephant Conservation Centre, Bangalore, India, p 62. http://www.asiannature.org/pdf_resources/ Kodagureport.pdf. Accessed 11 Aug 2009

Naughton-Treves L (1998) Predicting patterns of crop damage by wildlife around Kibale National Park, Uganda. Conservation Biology 12:156-168

Naughton-Treves L, Treves A, Chapman C, Wrangham R (1998) Temporal patterns of crop-raiding by primates: linking food availability in croplands and adjacent forest. Journal of Applied Ecology 35:596-606

Nelson A, Bidwell P, Sillero-Zubiri C (2003) A review of human elephant conflict management strategies. People and Wildlife Initiative Wildlife Conservation Research Unit. Oxford University, Oxford, p 25

Nyhus PJ, Tilson R, Sumianto (2000) Crop-raiding elephants and conservation implications at Way Kambas National Park, Sumatra, Indonesia. Oryx 34:262-274
O’Connell-Rodwell CE, Rodwell T, Rice M, Hart LA (2000) Living with the modern conservation paradigm: can agricultural communities co-exist with elephants? A five-year case study in East Caprivi, Namibia. Biological Conservation 93:381-391

Osborn FV, Parker GE (2003) Linking two elephant refuges with a corridor in the communal lands of Zimbabwe. African Journal of Ecology 41:68-74

Parker ISC, Graham AD (1989) Elephant decline: downward trends in African elephant distribution and numbers. Part I. International Journal of Environmental Studies 34:287-305

Pascal J-P (1982) Bioclimates of the Western Ghats at 1/250, 000. French Institute of Pondicherry, Pondicherry, p 2

Reilly J (2002) Growth in the Sumatran elephant (Elephas maximus sumatranus) and age estimation based on dung diameter. Journal of Zoology, London 258:205-213

Sitati NW, Walpole MJ, Smith RJ, Leader-Williams N (2003) Predicting spatial aspects of human-elephant conflict. Journal of Applied Ecology 40:667-677

Sitati NW, Walpole MJ, Leader-Williams N (2005) Factors affecting susceptibility of farms to crop raiding by African elephants: using a predictive model to mitigate conflict. Journal of Applied Ecology 42:1175-1182

Strauss AL, Corbin J (1998) Basics of qualitative research: grounded theory procedures and techniques, 2nd edn. Sage Publications, Newbury Park, p 336

Sukumar R (1989) The Asian elephant: ecology and management Cambridge studies in applied ecology and resource management. Cambridge University Press, Cambridge, p 255

Sukumar R (1990) Ecology of the Asian elephant in southern India. II. Feeding habits and crop raiding patterns. Journal of Tropical Ecology 6:33-53

Sukumar R (1994) Wildlife-human conflict in India: an ecological and social perspective. In: Guha R (ed) Social ecology. Oxford University Press, New Delhi, pp 303-317

Sukumar R (2006) A brief review of the status, distribution and biology of wild Asian elephants Elephas maximus. International Zoo Yearbook 40:1-8

Tchamba MN (1996) History and present status of the human elephant conflict in the Waza-Logone Region, Cameroon, West Africa. Biological Conservation 75:35-41

Theuerkauf J, Ellenberg H (2000) Movements and defecation of forest elephants in the moist semi-deciduous Bossematié Forest Reserve, Ivory Coast. African Journal of Ecology 38:258-261

Thouless CR, Sakwa J (1995) Shocking elephants: fences and crop raiders in Laikipia District, Kenya. Biological Conservation 72:99-107

Vidya TNC, Fernando P, Melnick DJ, Sukumar R (2005) Population differentiation within and amongst Asian elephant (Elephas maximus) populations in southern India. Heredity 94:71-80

Williams AC, Johnsingh AJT, Krausman PR (2001) Elephant-human conflicts in Rajaji National Park, northwestern India. Wildlife Society Bulletin 29:1097-1104

Wilson HS, Hutchinson SA (1996) Methodologic mistakes in grounded theory. Nursing Research 45:122-124 